\title{
Design and construction: changing the role
}

\author{
P. Rossi \\ DiPSA: Department for Project and Study of Architecture, \\ Roma Tre University, Italy
}

\begin{abstract}
Since the seventies many experiences have gone towards alternative or soft technologies, architecture for the poor, etc. In all of these the design was in answer to a need. Is it possible to consider building as an opportunity? Certainly, when the architecture is used, some functions or needs can be satisfied. But the building process itself represents a way to knowledge, a research field, a social event, a door opened on the future (while the need is a result of the past).

Within this area we could try to involve groups of non-experts in the design and construction process, which allows one to have a direct interface between individual needs and production. Specifically, during two workshops in secondary schools in central and southern Italy, the pupils have built from recycled material a theater stage in the first case and the stands for a little market in the second one. Some university students have guided the secondary students in the construction process using newspapers, cardboards, tetrapak and cables. A third project, larger than the others, consists of a modular shell, made by a folded wire mesh, covered with cement, sand, paper or fabric to self-build (thanks to the direct help of the university students) a family house for sick children in Kenya.

Decomposing design and building process in single phases is in accordance with the segmentation of industrial and economical processes of our contemporary world. Generally, nowadays architects are frustrated about this situation where they can't be the only "art director" anymore. On the other hand, if well managed, this segmentation can be the opportunity to receive at each step all those virtuous inputs, which can arrive from a widespread knowledge even if not structured and specialized in any way or from disposable resources like recycled materials, free work, etc.

Keywords: lightness, environment, shell, low cost, self-construction, innovation, technological transfer.
\end{abstract}




\section{Introduction}

I don't believe that the pattern of advanced countries can be the same to help the poor regions in their development processes. Specifically in the last period the basic technologies of the so-called western countries (or better, productive system) have been producing a growing distance between rich and poor nations in the world.

The way of forced industrialization means pollution, exploitation/exhaustion of human and natural resources, social costs. The current performances of China are exemplary. Even if the richness of the nation is growing up in a spectacular way, the quality of the air in the cities is a danger for the health of people, there aren't any laws or measures to protect the environment, nor to guarantee old and young workers. The damage will be paid by the next generations in a more than proportional price.

The enormous slums around the cities in Africa, Southern America or Asia are another dramatic manifestation of the uncontrolled contamination between different social and economic systems. Burning metal sheets are used as roofs under the African sun, dusty lands are full of houses without infrastructures, quotidian needs thwart every poly-annual project.

As Amartya Sen has demonstrated, the best results can be obtained by operating directly towards the culture of common people instead of waiting for the development of productive structure [1,2]. And the culture is not only theoretical or humanistic. I work in the field of material culture and in this field I look for a satisfactory result.

There are the evaluation criteria that change or should have to change in a project, not only humanitarian, but also environmentally and socially sustainable. While the advanced productive system needs a strengthening of infrastructures to regain competitiveness, in the backward situations more useful are the proposals with a low level of investments and capital. It's not a question between bamboo can and carbon fibre, but understand that hanger and famine have to be fought with different weapons from those of commercial competition [3].

\section{Working method}

What is the difference between learning by doing and knowing by doing? While learning is referred to something already known, which has to be reproduced, knowing signs a direction, an aim towards which to proceed. So doing assumes the role of the experimentation aimed to improve life and environmental quality. To be coherent with this assumption, the objective of the design process can't be established at the beginning, but it can be discovered step by step, during the experimentation. Before starting there are ties and opportunities that depend on the disposable resources in terms of involved people, geographical context and financial supports.

The ties assumed as the foundation of our experiments concern of:

Suitable technologies, referred to the buildings performances, the employed technologies and the use of natural resources $[4,5,6,7,8]$; 
Light structures, referred to the employed materials (which should be possibly renewable or recyclable), the structural morphologies and the industrial, manual and conceptual processes they imply $[9,10,11,12]$;

Temporary architectures, referred to the function and the historical presence of the buildings, which can exist during the lifetime of one or two generations or just for the duration of a specific event.

These three criteria help us, and our specific working teams, to guide the design towards a low environmental impact, a better social integration, and an improvement of the natural and anthropic environment.

\section{Young builders}

The way of experimentation started some years ago at the Environmental Design Course (Faculty of Architecture - Roma Tre University) where students extracted the form, the structure or structural behavior and the use from the matter/material. Obviously structures and materials are light to build envelopes that improve the habitability of the places. Shells and membranes are designed and verified mixing nets, cans, jute, threads or wires, some polymers, leafs, cotton, and others.

The difference between the described selection work and a traditional design process consists in the possibility to keep numerous variables for a same problem and crystallize them step by step while the single problems get clearer without never renouncing the starting criteria of suitability, lightness and temporarity which guarantee in nuce environmentally and socially coping responses.

At the end of this phase, which can be defined as intersection point between design and research, I have selected the best students' proposals in terms of practical feasibility, architectural and urban relevance, correspondence with the demand of potential users. It's mainly at this stage that the frontiers of technological innovation confront themselves with the emerging human needs, like those of the metropolitan disadvantage areas. But in this direction my efforts haven't produced any result.

To promote the culture of sustainability also out of University, my workgroup could try to involve groups of non-experts in the design and the construction process, with a direct interface between individual needs and athropic/physical/economic environment. Symmetrically some secondary schools have got in touch with the workgroup to be helped in their environmental education projects. Recently we have completed a stage for a school in Aprilia, close to Rome, using newspapers and boxes. Now we are engaged with a school at Morano Calabro (south of Italy) in the building of a temporary market.

Looking at the experiments or proposals of students in the Environmental Design course, some of the most interesting ones are based on the recycle of paper or cardboard packs. They can design a shell more or less suitable to the various opportunities that can arise to build these temporary architectures by cutting, folding, stitching or gluing the sheets,

The implicit building technique is to go back from container to sheet, to shape the sheet according to a geometrical law, to preview the resistant nervures, to 
realise the double sweep surfaces, to complete, if necessary, with some cables in order to stiffen and consolidate the shelter.

The commercial milk or juice containers loose immediately their characteristics to assume the new designed identity. This building activity helps to accept the traditional market, organized at the end of scholastic year to sell the objects made by students at Morano Calabro. The paper shells are thought as stands to show and sell the students production.

Moreover we are looking for jointing the paper or cardboard sheets with a photovoltaic film to make the shells self-sufficient in terms of energetic supplying for night lighting. The stratified origin of material used in packaging seems to suggest a diversified use of each layer to solve specific needs as the energetic autonomy.

Students pick up the containers for food or juice at home, neighbours or shops. Besides the simplicity in manipulating this material, the choice is motivated by the hope to compensate, even if in a small part, the waste produced by consumerism. This satisfies the didactical objectives of the jointed initiative to promote the environmental education. The aimed objectives are:

- educate the youths to take care of their environment developing a waste reclamation activity;

- revaluate to the manual skills as a tool to transform the prime matter;

- relate the knowledge with the doing;

- discover the natural and anthropic environments, observing the characteristics and the implications through the construction of a habitable envelope with own form, resistance, stability, lightness.

Before building the market envelope, university students have organized two workshops for secondary students, where they examined the geometrical law of the construction and the conditions of structural stability or resistance. Intuitively, if I transform food containers, I'll obtain a polygonal module to combine in the space. In this way I can realize a double curvature surface, but the polygonal module and the connecting system have to be thought to permit an angle between two close pieces. With the attention not to solve the problem designing a lot of different polygons, because the young constructors can have difficulties to follow too many complex instructions.

The CAD software easily permits to obtain a series of plane polygons from every kind of surface, but then I have to number each piece and the relative position on the surface. And this is not enough, because it becomes necessary to cut the pieces with much precision. A slight approximation, repeated many times, can make the building of the market envelope impossible.

The solution has been found by cutting the four corners in a particular way. This permits to fold the sides of the sheet to obtain the veins of curved shell and let the range of the polygons variation requested by the curvature.

So, the ninety per cent of the construction is made by the same piece, the rest needs special connections, adapted in progress (by university students).

A clear design strategy and the right balance between technical experience, figurative control and dilettantish spontaneity can concur to build sustainable and aesthetical architectonical results. 


\section{Low cost technologies}

Still now I have talked about building experiences that are between the play and the research. But, once engaged in the self-construction field, new ways are open, new aims become reachable.

A strong impulse to deepen the researches is derived from the meeting with a NGO, called AINA that works in Kenya to offer better life conditions for children. Now AINA is engaged to realize a family house for about twenty youths, positives at the HIV test. When they come out from the hospital, the local community tends to outcast these youths. So it was born the idea to organize a self-sufficient group in a small structure based on agricultural activities.

In the cooperation activities, architecture doesn't represent the central aim of the project. The humanitarian and economical objectives are the heart and the soul of the activities. Architecture plays a secondary role, as it can be useful to facilitate the objectives. The technology role can be different: introducing a new criterion in the use of a prime matter, promoting conditions for the self-knowing are qualified objectives in the cooperation activities [13, 14, 15].

So, when I've chosen poverty and cooperation as the theme of the university design course, students' work has left the traditional typologies or architectural organism spontaneously. They prefer reasoning directly around surfaces that separate an interior from an exterior to control climatic conditions, improve the habitability of a site. In this kind of approach, the envelope substitutes the functional distribution. The reference isn't a commercial target, with its consolidated preferences, habitudes, and behaviours. Facing poverty, the solution has to be searched simplifying the problems, accepting a partial satisfaction for more people than a better answer for few people.

The most interesting students proposals are based on three kinds of constructive systems. Someone prefers working with the bamboo can that is cheap and diffused in many poor countries. Some others prefer mud following the traditions of the local contexts. But I've tried to valorize a third kind of proposals, based on a new mix of materials that seems to be in conformity with two priority aims. At first, working in the field of lightweight structures has a better response to the environment (not only in the poor countries, but even in the rich and developed ones). Secondly, it could be an important opportunity for the local productive structure, compared with a different use of manual or primitive operational tools, to introduce a new vision of technology $[16,17]$.

In fact, a recurrent objective of the cooperation projects is the technological transfer towards the local enterprises. In this case the transfer isn't referred to a specific mechanical tool or manufacture that needs high investment, but shows how many different ways can valorize natural and anthropic resources, beginning from the human work that is easily disposable in the poor countries.

If the problem is organizing the work of about twenty university students to build a family house at Igoji (Kenya), what can this workgroup make in two or three weeks? What kind of materials are they able to manipulate? How are they integrating with the local productive structure? 
The definitive design of the family house has been based on some precise points:

1. the wire mesh can be easily folded (by cutting and superposing the borders) to obtain a shell with a double curvature. Since the wire mesh is sold in rolls 1 meter high and 25/30 meters long, the envelope has been divided in strips or arcs, jointed together to form a sort of tunnel. This form becomes solid and resistant with a jute fabric soaking with cement;

2. the comfort depends on ventilation more than on isolation. So the discontinuity of the tunnel (changing the dimensions of the section) guarantees the ventilation and there are enough local poor materials, like leaves, barks or straw, mixed with cement and sand, to insulate the envelope;

3. the energetic autonomy can be helped by photovoltaic cells distributed on the surface of the envelope.

Some parts of the family house have thought to be constructed by local building contractors. Specifically the groundwork, the internal walls and the hydric and electrical equipments are under the competence of some Kenyote operators.

Despite the choices about manual skills and non-expert workers, the architectural manufacture rising in my description has also a perfect feeling with the simulation software. Specifically the shell in wire mesh can be virtually constructed modeling the so-called NURBS (Non-Uniform Rational B-Splines) and jointing the different sections of every metal net strip. In a Loft-NURBS the arc on the border of the strip is smaller than in the centre, so we have a curved section of the strip that covers the arc. Introducing a variation criterion we have obtained a figurative performance of the envelope without modifying any other characteristic (low cost, self-construction, etc.). We have designed a non-circular arc, preferring a spiral section for the tunnel. If the spiral centre changes progressively strip by strip, the architectural volume acquires a dynamic image, following the recent aesthetic researches made by Miralles, Eiseman, Nox (just to remember the most famous ones). Finding a role to calculate the progressive differences of the distance between the folds that generate the double curvature of the shell is enough.

The virtual model is also necessary to complete the structural calculus that confirms how the shell form is resistant and stable with a thin thickness.

Before leaving for Kenya we have realized a prototype (about $5 \times 2 \times 3$ meters) of the tunnel at the AINA courtyard in Rome. The first tests haven't got a good result because: the net had a too much large mesh; the discontinuity of the curvature was a critic point during the assembly; the way to consolidate the shell with the cement was wrong, etc. Finally the building system went on.

Pulling near the folds the curvature ray of shell decreases. A more convex curvature offers a better resistance. Balancing the curvature of the arc and that of strip (orthogonal at the arc) it can be possible to obtain the desired stability and resistance. Immersing the jute fabric in a liquid mortar, the cement layer is distributed on the wire mesh regularly, without any specialised manufacture or workers. After the hardening, mesh, fabric and cement, become an only integrated material, to shape a rigid shell. Combining two layers with an empty 
space in the middle, the wall becomes aired in order to offer the best habitability in wet and hot regions.

\section{Conclusions}

Today the technology innovation collides with the architecture. It's organized and produced in two operational areas: the productive system that promotes a useful innovation in the increasing competitiveness, productivity, etc.; the scientific institutions that develop research programmes directly or indirectly oriented to consolidate the productive system. The architect role has a different aim, because it's closer to the coordination/control of operational tools (design methods, equipments, building techniques) more than to the invention of new technical tools. Specifically the self-construction is an argument without interest for industries, craftsmen, research centres, even if, this has a direct relationship with poverty, social outcasting, big geographical regions, most people in the world.

The best individual or collective satisfaction generally motivates more or less a radical renovation of the practice. But, because this happens, new tools or solutions are often necessary and, once again, they need inventions or ideas. The invention proceeds in a chaotic way, developing among many sectors and coming from unpredictable circumstances, sites or times. The duty of design is to manage the invention inside collective objectives, related to environment, economy, culture, society, etc.

It's difficult (and often useless) teaching or classifying the innovation, because each piece of information can be at the same time revolutionary or conservative. It depends on the context. For instance, many times the observation of nature has inspired the technical or scientific innovations, but many other times it has been the cause of ostracism towards the new approaches. It will be more useful, maybe, to promote the practice of innovation, choosing to be active subjects in an experimental research process, instead of limiting themselves to be the consignee of solutions invented by others.

\section{References}

[1] Amartya Sen, Development as Freedom, Anchor, 2000.

[2] Amartya Sen, Commodities and Capabilities, Oxford University Press, 1999.

[3] Jeremy Rifkin, The European Dream: How Europe's Vision of the Future Is Quietly Eclipsing the American Dream, Jeremy P. Tarcher, 2004.

[4] Bernard Rudofsky, Architecture Without Architects: A Short Introduction to Non-Pedigreed Architecture, University of New Mexico Press, 1987.

[5] Paul Oliver, Dwellings, Phaidon Press, 2003.

[6] E. Komatsu, A. Steen \& B. Steen, Built by Hand: Vernacular Buildings Around the World, Gibbs Smith Publishers, 2004.

[7] Bob Easton \& Lloyd Kahn, Shelter, Shelter Publications; 2000.

[8] Lloyd Kahn, Home Work: Handbuilt Shelter, Shelter Publications, 2004. 
[9] E. Kullmann, W. Nachtigall, J. Shurig \& other, IL 8: Nets in Nature and Technics, Institute of Lightweight Structures (IL), University of Stuttgart, 1975.

[10] K. Dunkelberg \& The Team of IL, IL 31: Bamboo, Institute of Lightweight Structures (IL), University of Stuttgart, 1985.

[11] J. Schlaich \& R. Bergermann, Light Structures, Prestel Books on Architecture, München 2003.

[12] M. McQuaid, Shigeru Ban, Phaidon Press Limited, London 2003.

[13] United Nations Human Settlements Programme The Challenge of Slums: Global Report on Human Settlements London and Sterling, VA: Earthscan Publications, 2003.

[14] K. Tranberg Hansen \& M. Vaa, Reconsidering Informality: Perspectives from Urban Africa, Nordiska Afrikainstitutet, 2004.

[15] I. Imparato \& J. Ruster Slum Upgrading and Participation: Lessons from Latin America (Directions in Development), World Bank Publications, 2003.

[16] Stanley Abercrombie, Ferrocement: Building with cement, sand, and wire mesh, Schocken Books, 1977.

[17] David Pearson, The New Natural House Book: Creating a Healthy, Harmonious, and Ecologically Sound Home, Fireside; 1998. 